\title{
The Impact of Coating layers and Additives on the Performance of Carbide Tools when Machining Inconel 718 Superalloy
}

\author{
Al-Watban A. S. PhD \\ Riyadh Technical College \\ Po Box 53699 \\ Riyadh 11593 \\ King Dom of Saudi Arabia
}

\begin{abstract}
Nickel based superalloys always considered as very difficult to machine materials due to their ability to retain high level of strength at elevated temperatures. In this work three different grades of cemented carbide tools with different geometries were used to machine nickel base, 718 , superalloy in order to compare their individual performances and also to determine the optimum cutting conditions. Three cutting speeds have been used for each tool with fixed feed rate during the machining. The temperature dependence of the micro-hardness of the WC materials was investigated from room temperature up to $1000^{\circ} \mathrm{C}$. The hot hardness results are correlated with the deformation mechanisms and micro-structural properties of the WC insert which control the response of the tool materials in service conditions.
\end{abstract}




\section{INTRODUCTION}

The fundamental reason which makes nickel-based alloys difficult to machine is their ability to retain high levels of tensile and shear strength at elevated temperatures.

In machining process, cutting action generates pressure and heat which then reduce the strength of workpiece materials and makes plastic deformation, shearing and chip formation quite easy. However, in the case of nickel-based alloys, high levels of strength are retained at temperatures above the maximum generated in most conventional machining operations.

Carbide tools, in the form of bulk and composite materials or coatings, seem able to cope with new challenges for cutting tools posed by high speed machining, even in the case of highly resistant alloys $[1,2]$. Despite this, more work has to be done as tool wear mechanisms are not globally understood for every combination of work material, tool material and cutting parameters.

With removal rates as high as $12 \times 10^{-6} \mathrm{~m}^{3} \mathrm{~s}^{-1}$ the machining of high resistance alloys with continuous chip type results in a condition of seizure between the chip and the rake face $[3,4]$. Chip shear strains near the tool surface can reach values close to 600 [4] and the heat generated by deformation raises the service temperatures to $1200^{\circ} \mathrm{C}$ [5]. This high stress-high temperature dynamic environment wears the tool, with the most deleterious effects being due to the combination of chemical and mechanical processes. Such is the case for an carbide tools insert when steel is turned; Inter-diffusion between the metal alloy and the tool materials [57], and serve abrasion by hard particles simultaneously occur as wear processes. The abrasive particles can either be tool material grains that come from rupture of the tool materials matrix after intergranular chemical corrosion by the interfacial layer between the work-piece and the carbide tool rake face [3]-or chromium carbide precipitates from the nickel-based superalloy, Inconel 718.

Cutting tests are a straightforward but theoretically complex way to investigate the performance of tool materials. It is still a research goal to create the extremely difficult conditions of cutting by means of any other type of controlled laboratory tests. Modified wear tests $[8,9]$, chemical wear studies with static diffusion tests $[5,10,11]$, and high temperature mechanical testing are examples of this approach. Among the mechanical tests, hot hardness is commonly considered to be the best method to simulate the effect on the tool surface during cutting [12-15]. In the absence of seizure conditions, or when seizure is broken, the contact between the metal and the tool is through microasperities which impose similar stress fields as those of the indenter in the hot hardness tests $[16,17]$. When hot hardness experiments are 
done in vacuum, the atmosphere-free condition that is found in the contact between chip and the tool [4]is supposedly similar. The effect of coating layers and the relationship between the hot hardness test and crater wear in nickel cutting with carbide inserts is investigated further in this study.

\section{EXPERIMENTAL AND MATERIALS DETAILS}

The MAHO (CNC) lath machine was used for all the machining tests. This machine tool has working area with center distance of $1550 \mathrm{~mm}$, saddle movement (z) of $1390 \mathrm{~mm}$ and cross slide movement of $450 \mathrm{~mm}$. It has two speeds ranges from 30-900 rpm for gear A and from 130 rpm two $2900 \mathrm{rpm}$ for gear B. The main motor power is $40 \mathrm{Kw}$ and the maximum spindle torque is $1500 \mathrm{~nm}$.

The composition of the carbide tools and the workpiece were shown in table 1 and 2. As shown in table 1 the $\mathrm{KC} 950$ carbide inserts were coated with three layers of $\mathrm{TiC}, \mathrm{Al}_{2} \mathrm{O}_{3}$ and TiN respectively. The KC850 tools also have multi-layer coating of TiC, TiC-N and TiN respectively. The major difference between the KC850 and KC950 grade is the intermediate layer which is in the case of $\mathrm{KC} 850$ is $\mathrm{TiC}-\mathrm{N}$ and $\mathrm{Al}_{2} \mathrm{O}_{3}$ for $\mathrm{KC} 950$. The two grades have similar substrate material as can be seen in the table1. The third grade of carbide tools used is the K68 uncoated inserts which is referred to as a very abrasion resistance, general purpose grade with superior machining qualities. The composition of grade K68 are also shown in table 1. The nickel based Inconel 718 superalloy used for the test represents the nickel based superalloy group and is one of the most widely used in the hot section parts of the aircraft engine. The chemical composition of the work materials is shown in table2.

Table 1. Composition of Cemented Carbide Tools, grade KC950, 850 and uncoated K68

\begin{tabular}{|c|c|c|c|c|c|c|}
\hline \multicolumn{2}{|c|}{$\begin{array}{c}\text { Tool } \\
\text { grade }\end{array}$} & WC & TiC & Ta(Nb)C & Co & \multicolumn{2}{c|}{ Coating } \\
\cline { 5 - 8 } & & & & & Type & $\begin{array}{c}\text { App. } \\
\text { Thickness }\end{array}$ \\
\hline KC950 & 83.6 & 4.4 & 6 & 6 & TiC/Al $\mathrm{O}_{3} / \mathrm{TiN}$ & $4 / 2 / 3$ \\
\hline $\mathrm{KC} 850$ & 85.4 & 2.5 & 6.1 & 6 & TiC/TiCN/TiN & $4 / 2 / 3$ \\
\hline $\mathrm{K} 68$ & 92.0 & 2 & - & 8 & \multicolumn{2}{|c|}{ Uncoated } \\
\hline
\end{tabular}

Room temperature hardness was measured using a Vickers indenter with a $9.8 \mathrm{~N}$ load, the hardness being the average of 20 indentations for each sample. The room temperature indentation fracture toughness $\mathrm{K}_{\mathrm{IC}}$ was determined according to Niihara's expression [20]. For 
the hot hardness measurements, the samples were sectioned and the surfaces parallel to the hot pressing direction were polished with $1 / \mu \mathrm{m}$ diamond paste. The hot hardness experiments were carried out in a temperature-controlled micro-hardness tester operating under a vacuum $\left(10^{-4} \mathrm{~Pa}\right)$. The Vickers hot hardness was measured using a $4.9 \mathrm{~N}$ load and $15 \mathrm{~s}$ of indentation time. Hardness tests were performed from room temperature up to $1000^{\circ} \mathrm{C}$ in steps of $100^{\circ} \mathrm{C}$ with five indentations at each temperature. Indentation diagonal lengths were measured outside the apparatus using an optical microscope.

For turning, the tests were carried out by using one insert with the same geometry for each grade (SNMP 1204 12). The ISO designation of these inserts which includes seven symbols, four letters and three numbers. The letters are related respectively to the insert shape, clearance angle, tolerances and the type of insert, while the numbers are related to the insert length, insert thickness and the nose radius.

The cutting speed was in the range $2.4-3.9 \mathrm{~ms}^{-1}$, the feed $f$ was kept constant at $0.25 \mathrm{~mm} \mathrm{rev}^{-1}$, and the depth of cut (DOC) took values in the range 1-4 mm. Conventional tool wear parameters were measured using optical microscopy: mean flank wear (VB); maximum cater depth (KT); distance between tool edge and creater center (KM). The crater wear rate was calculated as $\Gamma_{\mathrm{K}}=(\mathrm{KM} . \mathrm{KT}) / t$.

Table 2. Workpiece Materials

\begin{tabular}{|c|c|c|c|c|c|c|c|}
\hline \multicolumn{7}{|c|}{ Chemical Composition of Inconel 718 } \\
\hline $\mathrm{Ni}$ & $\mathbf{C r}$ & $\mathrm{Fe}$ & $\mathrm{Mo}$ & $\mathrm{Ti}$ & $\mathrm{Al}$ & $\mathrm{Nb}$ & $\left(\mathbf{H}_{\mathrm{v}}\right) \mathbf{M P a}$ \\
\hline 57.5 & 19 & 18.5 & 3 & 1 & 0.5 & 5 & 504 \\
\hline
\end{tabular}

\section{RESULTS}

The results of the Inconel 718 cutting tests are presented in Table 3 . Hot hardness results are given in table 4. All the samples from the $\mathrm{KC} 950, \mathrm{KC} 850$ and $\mathrm{K} 68$ sample were fully densified. 
Table 3. Cutting Parameters and Wear in Steel Tool Turning Tests

\begin{tabular}{|c|c|c|c|c|c|c|c|c|}
\hline $\begin{array}{c}\text { Insert } \\
\text { Type }\end{array}$ & $\begin{array}{c}T \\
(s)\end{array}$ & $\begin{array}{c}\mathrm{DOC} \\
\left(10^{-3} \mathrm{~m}\right)\end{array}$ & $\begin{array}{c}F \\
\left(10^{-3} \mathrm{~m}\right)\end{array}$ & $\begin{array}{c}v_{\mathrm{c}} \\
(\mathrm{m} / \mathrm{s})\end{array}$ & $\begin{array}{c}\mathrm{VB} \\
\left(10^{-3} \mathrm{~m}\right)\end{array}$ & $\begin{array}{c}\mathrm{KM} \\
\left(10^{-3} \mathrm{~m}\right)\end{array}$ & $\begin{array}{c}\mathrm{KT} \\
\left(10^{-3} \mathrm{~m}\right)\end{array}$ & $\begin{array}{c}\Gamma_{\mathrm{K}} \\
\left(10^{-9} \mathrm{xm}^{2} \mathrm{~s}^{-1}\right)\end{array}$ \\
\hline $\mathrm{KC} 950$ & 35 & 1 & 0.25 & 3.6 & - & 0.628 & - & - \\
& 15 & 1 & 0.25 & 3.6 & 0.776 & 0.512 & 0.300 & 10.2 \\
& 15 & 1 & 0.25 & 3.6 & 0.848 & 0.504 & 0.285 & 9.6 \\
& 15 & 1 & 0.25 & 3.6 & 0.836 & 0.512 & 0.250 & 8.5 \\
& 15 & 2 & 0.25 & 3.6 & 0.824 & 0.544 & 0.240 & 8.7 \\
& 15 & 4 & 0.25 & 3.6 & 0.832 & 0.516 & 0.275 & 9.5 \\
& 52 & 1 & 0.25 & 2.6 & - & 0.803 & 0.275 & 4.2 \\
& & & & & & & & \\
$\mathrm{KC} 650$ & 12 & 2 & 0.25 & 3.9 & 0.520 & 0.224 & 0.110 & 2.1 \\
& 12 & 4 & 0.25 & 3.9 & 0.532 & 0.320 & 0.100 & 2.7 \\
& 60 & 1 & 0.25 & 3.9 & 0.980 & 0.448 & 0.225 & 1.7 \\
& & & & & & & & \\
$\mathrm{~K} 68$ & 12 & 2 & 0.25 & 3.9 & 0.520 & 0.224 & 0.110 & 2.1 \\
& 12 & 4 & 0.25 & 3.9 & 0.532 & 0.320 & 0.100 & 2.7 \\
& 60 & 1 & 0.25 & 3.9 & 0.980 & 0.448 & 0.225 & 1.7 \\
& & & & & & & & \\
\hline
\end{tabular}

Arrhenius values of hardness versus $1 / \mathrm{T}$ are adequate to show the hardness of polycrystalline ceramics at high temperature and to assess the contribution of thermally activated deformation mechanisms [16-22]. Two temperature ranges are observed in the hardness of the carbide materials when $H$ is consederd as a decreasing exponential function of $T$ :

$$
H=H_{0} \exp (-a T)
$$

The low temperature range goes from room temperature up to $800^{\circ} \mathrm{C}-900^{\circ} \mathrm{C}$, and the high temperature range is above this point. The wear rates of the carbide materials are proportional to the reciprocal given powers of hardness [17-23]. Consedering the dependence of In $(H)$ as a function of $T$ (table 4 ), the relative changes in $H$ are emphasized as are the potential changes of the material wear resistance.

Table 4. Hot Hardness (Arrhenius values) of Carbide Tools

\begin{tabular}{|c|c|c|c|}
\hline \multirow{2}{*}{} & \multicolumn{3}{|c|}{ Ln H } \\
\hline Temperatures ${ }^{\circ} \mathbf{C}$ & KC950 & KC850 & K68 \\
\hline 0 & 3 & 2.8 & 2.7 \\
200 & 2.95 & 2.75 & 2.6 \\
400 & 2.9 & 2.55 & 2.51 \\
600 & 2.85 & 2.5 & 2.35 \\
700 & 2.8 & 2.4 & 2.3 \\
800 & 2.7 & 2.2 & 2.1 \\
900 & 2 & 1.8 & 1.5 \\
1000 & 1.9 & 1.4 & 1.2 \\
\hline
\end{tabular}




\section{DISCUSSION}

Permanently strained impressions are the result of different deformation mechanisms that brittle materials exhibit under the stress field that is generated by an indenter. At high temperature, micro-plasticity is reported to be the dominant deformation mode [24].

The deformation mechanisms can be classified into two broad categories [16-25]: (i) grain processes (dislocation motion, twinning, micro-cracking) and (ii) grain boundary processes (grain boundary dislocation activity, diffusional flow).

Table 4 shows that hot hardness in the high temperature range, i.e. above $800^{\circ} \mathrm{C}-900^{\circ} \mathrm{C}$, has much stronger temperature dependence than it has in the low temperature range. Softening of the intergranular phase of the carbide by the activation of grain boundary processes has been reported at these temperatures $[21,26]$.

The amount of cobalt, as given in Table 1, also has a remarkable effect in decreasing hot hardness in the high temperature range, as can be seen by comparison of the values of the KC950, KC850 and K68 samples, (table 4). The diffusional flow rate of the mechanism that is expected to be effective at high temperatures [30] is proportional to the grain boundary film thickness.

The activation energy of high temperature hardness for a given batch, for instance that of the KC950 samples, would not be expected to show any difference because the intergranular paths for diffusion controlled deformation are chemically identical. However, each sample of the batch differs in its second phase content (Table 1), the content of cobalt is identical in KC950 and KC850. The grain size is similar for KC950 and KC850 and coarser for the K68 sample. The effects of fine grain size and cobalt content on the room temperature hardness combine so that the K68 sample has the highest hardness in the low temperature range [29]. By using the 'compensation law' [29-32], which states that the pre-exponential factor and activation energy of hardness as well of other diffusion-controlled processes of matter transport are linked together, a single activation energy $\mathrm{Q} \approx 500 \mathrm{~kJ} \mathrm{~mol}^{-1}$ was calculated at the high temperature for the high temperature deformation mechanism of hardness [29]. This value of the activation energy is of the same magnitude as the activation energy of W-C grain boundary diffusion in carbide materials [32], thus denoting that creep by diffusional flow, a grain boundary process, is the controlling mechanism of high temperature indentation of carbide materials.

The main characteristic of the worn carbide surfaces after nickel machining, as observed by scanning electron microscopy, are the improved resistance of the KC950 inserts to the effects of abrasion and corrosion due to the existence of the multilayer coatings. Since the abrasive 
wear resistance is increased by the material hardness better performance is anticipated for the values of hot hardness of the KC950 insert. Plastic deformation of surface grains, fracture of material by lateral flaws, both alongside and ahead of the slider, and dissolution of the ceramic material in the reactive tribolayer between the WC tool surface and the metallic chip contribute to the wear of the ceramic rake face in the condition of seizure. Each contribution is dependent on the values of the cutting force $F_{c}$, cutting speed $v_{c}$, the concentrations of hard inclusions, such as the carbide precipitates in the work-piece, and the amount of ceramic grains that are pulled out and slide on the tool surface, $[3,30]$. Increasing the temperature of the rake face at this contact with change the contributions of the wear mechanisms - encouraging more dissolution and a softer cutting surface. The lower strength of the ceramic at high temperature also enhances the inter-granular process of mechanical failure. Before extensive reactions come into the wear process, the brittle mode and plastic, yield of surface grains will compete in parallel ways, despite the changes in contact temperature with cutting speed.

The volume removed by abrasive wear, as described by the three-dimensional model of wear by lateral flaws occurring ahead of the slider, is a function of the load $P$, the material toughness $\mathrm{K}_{I C}$ and hardness $H[23]$ such that

$$
\frac{V}{l}=\frac{A P^{7 / 6}}{K_{I c}^{2 / 3} H^{1 / 2}}
$$

Where $V$ is the volume of material removed, $l$ is the sliding length and $A$ is a constant. At constant values of $P$, the wear rate $d V / d t$ is proportional to the sliding velocity $d l / d t$, the proportionality factor being itself dependent on the speed whenever the material properties $\mathrm{K}_{I C}$ and $H$ are changed by the contact temperature. The exponents of $P$ and $K_{I C}$ in equation (2) will change to $5 / 4$ and $3 / 4$, respectively, for lateral - crack- dominated abrasive wear [31]. The volume removed becomes a single function of $P$ and $H$, the exponent of $H$ being increased to 1, for plastic-dominated wear, accordingly to Archard's law [32].

The total heat of cutting, which is equal to the cutting power, arises from shear in the primary shear plane and in the secondary flow zone and from frictional heat on the flank land. For high metal removal rates, $85 \%-90 \%$ of the heat is removed by the metallic chip [4]. The fraction of heat that is generated by secondary shear in the thin flow zone may amount to more than $20 \%$ of the total heat. As the heating in the flow zone is highly localized, steep thermal gradients are created between it and the bulk of the tool and the chip. Heat diffuses away from this zone in proportion to the thermal conductivity of the ceramic tool and the work-piece material and the temperature difference between this zone and the average temperature in the 
bulk of the tool and work-piece. Low temperature chip material is continuously arriving at the metal side. As thermal conductivity of the metal is higher than that of the WC insert, the values of the rake face temperature become controlled by the metal heat capacity, $c$, density $p$, thermal conductivity $\mathrm{K}$ and specific cutting energy $E$ [32] such that

$$
T=E\left(\frac{v_{c} f}{K P_{c}}\right)^{p}
$$

Where $f$ is the feed, and $T$ is the contact temperature in degree Celsius, taking room temperature to be approximately $0{ }^{\circ} \mathrm{C}$. At the maximum value of the temperature function (equation (3)), the exponent is $p=1 / 2$. Heat losses, changing contact geometries and uncertainly of rake face temperature measuring techniques result in the experimental values of $p$ being in the range $1 / 3 \leq p \leq 1 / 2$. The values of $p$ for cutting of mild and alloy steels are fairly stable [4]. A low value of $p \approx 1 / 4$ was reported in cutting of engineering steel and other functional dependence's of $T$ on $v_{c s}$ such as $T \alpha \ln \left(v_{c}\right)$, have also been fitted to the measured values of the rake face temperature [4].

The metal properties $K, p, c$ and $E$ undergo minor changes with temperature in the temperature ranges that are found in the secondary flow zone [4]. Above a low threshold speed close to $v_{\mathrm{c}}$ $\approx 0.5 \mathrm{~m} \mathrm{~s}^{-1}$, the cutting forces for mild and alloy steels are almost constant for wide ranges of $v_{\mathrm{c}}$. The ratio of cutting force $F_{\mathrm{c}}$ to DOC is constant for fixed values of the feed rate and cutting speed. The toughness of WC materials is independent of temperature for values of $T$ below $1000^{\circ} \mathrm{C}-1100^{\circ} \mathrm{C}[31]$. The exact value of $\mathrm{K}_{I C}$ is dependent on the measuring technique. The room temperature values of indentation $K_{I C}$ of the ceramic inserts is given in Table 4 . The sharp rise in the measured values of $K_{\mathrm{IC}}$ of WC that is often observed above $900^{\circ} \mathrm{C}$ is due to crack blunting, softening and yield of the inter-granular cobalt phase. At such temperatures the ceramic reacts strongly with the chip and the hardness of WC decreases so rapidly that the tip survives service. The major effect of heat on the absorption wear resistance of the crater of the WC comes through the dependence of $H$ on $T$. At fixed values of feed, $\Gamma_{\mathbf{k}}$ becomes a function of cutting speed:

$$
\Gamma_{k}=\left(\frac{A F_{c}^{7 / 6}}{K_{l c}^{2 / 3} D O C}\right) \frac{v_{c}}{H^{1 / 2}}
$$

The factors inside the parentheses are constant but the value of $H$ is dependent on $v_{\mathrm{c}}$ (cf. equation (3)). The dependence of $T$ on $v_{\mathrm{c}}$ was calculated from experimental values of $T$ in cutting of mild steel such that $T \approx 800 v_{c}{ }^{l / 3}\left({ }^{\circ} \mathrm{C}\right)$ [4]. The value of $T=1070{ }^{\circ} \mathrm{C}$ is calculated at $v_{c}=$ 
$2.6 \mathrm{~ms}^{-1}$. Comparison of the upward bending of $\Gamma_{\mathrm{k}}$ of $\mathrm{KC} 850$ in table 3 and of the corresponding bending in the $H$ values in table 4 shows that at $1100^{\circ} \mathrm{C}$ the hardness is low and rapidly decreasing. By adjusting the calculated values of $\Gamma_{k}$ (equation (4)) to match the experimental values at $v_{c}=2.6 \mathrm{~ms}^{-1}$ in $\mathrm{KC} 950$ and $v_{\mathrm{c}}=2.4 \mathrm{~ms}^{-1}$ in $\mathrm{KC} 850$, the following values of the proportionality constant in parenthesis in equation (4) were obtained: $1.38 \times 10^{-4} \mathrm{~Pa}^{1 / 2} \mathrm{~m}$ and $0.66 \times 10^{-4} \mathrm{~Pa}^{1 / 2} \mathrm{~m}$ respectively.

The slope of the calculated lines in table 3 varies with the room temperature hardness of the carbide, the temperature coefficient of $H$, the constant $a$ in equation (1) and with the exponent of hardness in the abrasive wear rate (equation 4)). As the hardness of the KC950 insert is higher at room temperature and at high temperatures, the corresponding $\Gamma_{\mathrm{k}}$ has a lower slope in table 3. Given the dependence of $H$ on $T$ as shown in table 4 , the $\Gamma_{\mathrm{k}}$ curves would diverse further if Archard's law of plastic-dominated wear is tentatively used. At the same cutting speed, the KC850 insert wears more than the KC950 insert. There is a trend for higher cutting forces with increasing tool wear $[4,20]$ but the cutting forces were not measured in this study. From the values of the proportionality constants that are calculated above, the cutting forces for machining tool steel with the KC950 insert, which better resisted wear, would have been lower (about 0.50 ) than those of the KC850 insert.

The results in table 3 show that crater wear of the KC950 insert for the range of cutting speed investigated was due to abrasion. For cutting speeds above $v_{\mathrm{c}} \approx 2.5 \mathrm{~ms}^{1}$ the creater wear of the $\mathrm{KC} 850$ insert has an additional contributing factor that enhances wear. Chemical wear due to reactions between the tool and the metallic chip was observed with the KC850 [3]. The chemical reactions corrode the grain boundary phase and locally decrease the glass viscosity. A continuous narrow layer that was observed at the trailing edge of the creater in the KC 850 insert, which is mainly composed of cobalt, titanium carbide impurities (iron and calcium) and nickel, indicated chemical wear by local corrosion of the intergranular phase [3]. The mechanical effects of grain pull-out, ploughing and scoring of the reaction layer increase the reaction rates on the wear surface. As the viscosity of the $\mathrm{TaC}$ grain boundary phase of the $\mathrm{KC} 950$ insert is higher than that in the KC850 insert, the diffusivity of the metallic elements in the grain boundaries is slower. The cutting performance of the KC950 insert remains stable as the potential contribution of chemical wear is moved to higher values of cutting speed, outside the speed range shown in table 3 . The high viscosity of the nitrogen-rich grain boundary phases was equally important for the high temperature hardness. The procedure established above-allows us to separate the intragrain and intergranular processes of hot hardness at low 
temperature from the contribution of viscous flow. The values of $\Gamma_{k}$ in table 3 follow the trend that was established above for the high temperature mechanisms controlling the hot hardness. The cutting speed corresponding to the inflection point of the wear rate (table 3 ) can be used as a definition to limit the cutting speed of the WC inserts [3]. This speed limit is related to the onset of enhanced grain boundary corrosion, softening of the intergranular phase, grain pullout and intensive ploughing of the crater surface of the KC850 inserts. As discussed above, the $\mathrm{TaC}$ glass of the KC950 is more creep resistant and both the hot hardness and crater wear resistance are improved.

\section{CONCLUSIONS}

The cutting performance of $\mathrm{KC} 950$ was improved due to the multiplayer coating and the $\mathrm{TaC}$ quantity. Intergranular phase yielding is considered to be responsible for the drastic decrease in the insert materials strength, both in the hot hardness tests and in cutting. If the hot strength of the ceramic, which can be assessed by hot hardness, is not enough to support the cutting stresses, and this is the case for KC850 close agreement between the limiting speed for tool degradation in cutting and the transition temperature of hot hardness is predicted. $\mathrm{TaC}$ intergranular phase in WC promotes tool resistance in cutting conditions that are drastically aggravated such as those which are found in nickel turning.

\section{REFERENCES}

[1] C. A. Brookes and A. S. Alwatban, Hard Materials, 77-87 5 (1994).

[2] E.D. Whitney, Powder Metall. Int., 15(4), 201-205 (1983).

[3] R.F. Silva, J.M. Gomes, A.S. Miranda and J.M. Vieira, Wear, 148, 69-89 (1991).

[4] E.M. Trent, Metal Cutting, Butterworth, Guildford (1984).

[5] S.T. Buljan and S.F. Wayne, Wear, 133, 309 - 321 (1989).

[6] B.M. Kramer and N.P. Suh, ASME Trans. J. Eng. Ind., 102(3), 303-309 (1980).

[7] E.O. Ezugwu and J. Wallbank, Mater. Sci. Technol., 3, 881-887 (1987).

[8] M. Olsson, S. Soderberg, S. Jacobson and S. Hongmatk, Int. J.Mech. Tools Manufact., 29(3), 377-390 (1989).

[9] D. Agranov, D. Brandon and R. Wertheim, Ind. Ceram., 8(4), 192-197 (1988).

[10] S.T. Buljan and S.F. Wayne, Adv. Ceram.Mater., 2(4), 813-816 (1987).

[11] J.A. Yeomans, PhD Dissertation, University of Cambridge, Cambridge, UK (1986).

[12] C. Greskovich and H.C. Yeh., J.Mater. Sci. Lett., 22, 657 - 659 (1983).

[13] G.N. Babini, A. Bellosi and C. Galassi, J. Mater. Sci., 22, 1687-1693 (1987).

[14] T. Ekstrom and J. Persson, J. Am. Ceram. Soc., 73 (10), 2838 (1990).

[15] A.K. Mukhopadhyay, S.K. Datta, D. Chakraborty, J. Euro. Ceram.Soc., 6, 303-311 (1990).

[16] M.G.S. Naylor and T.F. Page, Tech. Rep. no. DA-ERO-78-G-010, Cambridge (1981).

[17] R.R. Rice, Treatise on Materials Science and Technology, vol. 11 (R.K. MacCrone, Ed.), Academic Press, New York. (1977).

[18] J. Mukeriji, P.K. Das, P. Greil and G. Petzow, Ceram. Int. 13, 215-22l (1987). 
[19] C.P. Gazara and D.R. Messier, Ceram. Bull., 56 (9), 777-780 (1977).

[20] K. Niihara, R. Morena and D.P.H. Hasselman, J. Mater. Sci. Lett., 1, 13-16 (1982).

[21] K.Niihara and T. Hirai, Powder Metall. Int., 16(5), 223 - 226 (1984).

[22] W. Kollenberg and H. Schneider, J. Am. Ceram. Soc., 72(9), 1739-1740 (1989).

[23] E. Ling and I. Finnie, Key Eng. Mater., 33, 49 - 76 (1989).

[24] Lankford, J. Mater. Sci., 18, 1666 - 1674 (1983).

[25] P.C. Dokko and J.A. Pask, Mater. Sci. Eng., 25, 77-89 (1976).

[26] K. Tsukuma, M.S. Shimada and M. Koizumi, Ceram. Bull., 60 (9), $910-912$ (1981).

[27] S. Hampshire, P.A.L. Drew, K.H. Jack, Comm. Am. Ceram. Soc., 67, C-46 C-47 (1984).

[28] D.R. Messier and A. Broz, Common. Am. Ceram. Soc., 65, C-123 (1982).

[29] A. S. Alwatban, MsC Dessertation, Warwick University, Coventry, UK (1991)

[30] H.J. Frost and M.F. Ashby, Deformation Mechanism Maps, Pergamon Press, New York (1982).

[31] P. Drew and M.H. Lewis, J. Mater. Sci., 9, 261 - 269 (1974).

[32] T. Dosdale and R.J. Brook, J. Am.Ceram. Soc., 66 (6), 392. 